International Journal of Food Science, Nutrition and Dietetics (IJFS)

ISSN 2326-3350

\title{
Studies on Effect of Different Extraction Methods on The Quality of Pomegranate Juice And Preparation of Spiced Pomegranate Juice
}

Priyanka P', Sayed H.M ${ }^{2}$, A.A Joshi ${ }^{3 *}$,Jadhav B.A ${ }^{4}$, Chilkawar P.M

1 Student College of Food Technology,Associate Professor College of Food Technology, India

2 S. R. A. Department of Food Chemistry and Nutrition College of Food Technology, India

$3 *$ RA College of Food Technology Department of Food Chemistry and Nutrition, India

4 SRA Naigaon college of food technology, Nanded, India

5 Marathwada Agricultural University, Parbhani-431401, India.

\section{Abstract}

The present investigation was carried out to standardize the method of extraction of juice and to study the effect of extraction method on yield and quality of pomegranate juice. Also the efforts were also made to standardize the recipe for preparation of spiced pomegranate juice by using selected processing techniques and explore the prepared product for commercial use. Further efforts were made to evaluate the chemical quality of prepared pomegranate juice enriched with spices for their nutritional and organoleptic quality. The juice was also analysed for shelf life study on both i.e. at room as well as refrigeration temperature and techno-economic feasibility of spiced pomegranate juice was also assessed.

\section{*Corresponding Author:}

A.A Joshi,

RA College of Food Technology Department of Food Chemistry and

Nutrition, India

E-mail: anjali_cft31@rediffmail.com.

Received: May 23, 2014

Accepted: June 18, 2013

Published: June 25, 2013

Citation: A.A Joshi, et al (2013) Studies on Effect of Different Extraction Methods on The Quality of Pomegranate Juice And Preparation of Spiced Pomegranate Juice. Int J Food Sci Nutr Diet. 2(5), 51-55. doi: http://dx.doi.org/10.19070/2326-3350-1300010

Copyright: A.A Joshi. ${ }^{\circ} 2013$ This is an open-access article distributed under the terms of the Creative Commons Attribution License, which permits unrestricted use, distribution and reproduction in any medium, provided the original author and source are credited.

\section{Introduction}

Pomegranate is an important crop for dry land areas in India. The two varieties i.e. Ganesh and Arakta were used for the present study. Kandhari/ Arakta which is large sized with deep red rind, arils dark blood red, hard seedsand slightly bitter juice. And Ganesh variety with Medium sized; soft seeds; pinkish flesh and juice with agreeable taste. Generally these fruits are used for table purpose; however they are also processed into va-rieties of products like juice, squash, syrup, wine, anar-rub and anardana ( $\mathrm{La}$ Rae, 1969). The special structure of fruit is one of main factors which limit its industrial processing. The fruits can be preserved and processed into different products like juice, squash, syrup, jelly, wine, anardana and canned beverages.

The juice from fresh pomegranate fruit is an excellent cooling beverage for alleviating thirst in cases of fever and sickness. It acts on liver, heart and kidneys and tones up their functions. It supplies the required min-erals and helps the liver to preserve the vi- tamin from the food. It also increases the body resistance against infections. The juice is an excellent cooling beverage for alleviating thirst in cases of fevers and sickness. It also increases the body resistance against infections (Seeram et al., 2008). The juice particularly tannin frac-tion, reduces lipid peroxidation, cellular cholesterol, accumulation and development of atherosclerosis (Es-maillzadeh et al., 2004). Commercialization of process technology and pomegranates products in market is very important to improve economy. Knowing the im-portance of health benefits of pomegranate and all re-lated aspects, the present investigation entitled "Studies on effect of different extraction methods on the quality of pomegranate juice and preparation of spiced Pomegranate juice" was carried out to standardize the recipe for preparation of spiced pomegranate juice by using selected processing techniques and explore the prepared product for commercial use. Further efforts were made to evaluate the chemical quality of prepared pomegranate juice enriched with spices for their nutritional and organoleptic quality. Techno-economic fea-sibility of spiced pomegranate juice was also assessed.

\section{Materials And Methods}

Pomegranate fruits of cultivars Ganesh and Arakta were selected from local market. The fruits of uniform size, colour and maturity were selected by visual obser-vation and used as experimental material. Spices like cardamom, clove, fennel and other material required for preparation of spiced Pomegranate juice were procured from local market.

- ProximateAnalysis of spiced pomegranate juice: Prepared pomegranate juice and spiced pomegranate juice were analyzed for its chemical quality by standard methods (AOAC, 1990).

- Sensorial Analysis: Sensory analysis of prepared products was performed by using standard method (Amerine et al., 1987).

-Statistical analysis: The analysis of variance of the data obtained was done by using Completely Randomized Design (CRD) 
Figure 1: Clarification of Pomegranate Juice

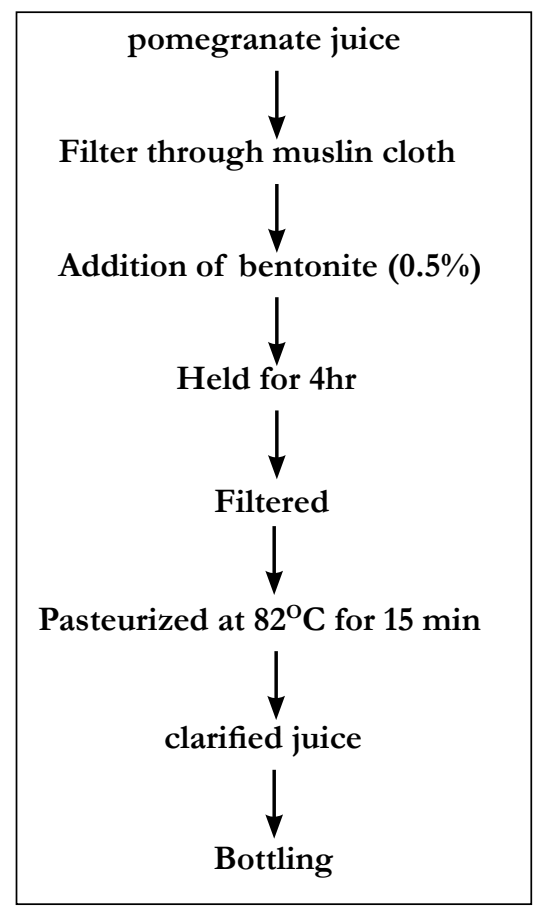

for different treat-ments as per the methods given by Panse and Sukhatme (1967). The analysis of variance revealed at significance of $\mathrm{P}<0.05$ level, S.E. and C.D. at $5 \%$ level is mentioned wherever required.

\section{Extraction of Juice}

Hand Press Method (M1): Pomegranate juice arils were separated manually from fruit. The juice was extracted by crushing the arils followed by pressing through two to three layers of muslin cloth

Domestic Mixer Method (M2): Pomegranate juice arils were separated manually from fruit. The sepa-rated arils were crushed in domestic mixer. The juice obtained is strained by using muslin cloth.

Clarification of juice: The filtered pomegranate juice was used for clarification using commercially available fining agent gelatin and bentonite. Firstly juice was filtered through muslin cloth. To this juice bentonite at $0.5 \%$ of juice was added and juice was held for 4 hrs. Then the treated juice was filtered through muslin cloth. This juice was pasteurized at $82^{\circ} \mathrm{C}$ for $15 \mathrm{~min}$. to get clarified juice.

\section{Storage Studies of Pomegranate Juice and spiced Pomegranate juice}

Pomegranate spiced juice was analyzed for various attributes on every $15^{\text {th }}, 30^{\text {th }}, 45^{\text {th }}, 60$ th day and shelf life studies were carried out for a period of 2 months. The pomegranate juice samples were stored at ambient temperature $\left(27-28^{\circ} \mathrm{C}\right)$ and at refrigerated temperature $\left(4-5^{0} \mathrm{C}\right)$.

Assessment of Energy Value of value added products: Theoretical energy value of the spiced juice was calculated on the basis of proximate chemical compo-sition.

Assessment of Techno-Economical Feasibility: The production cost of spiced juice prepared from pomegranate was cal- culated by considering the cost of raw material, processing and packaging cost.

\section{Results And Discussion}

It is observed from Table1 that on the basis of whole fruit, percent juice yield by hand press method (M1) and domestic mixer method (M2) in Ganesh cultivar was 50.25 and 55.50 percent while in Arakta cultivar 50.20 and 55.00 percent respectively. It was noted that higher juice yield was obtained for both cultivars us-ing mixer due to crushing of whole seeds. The juice obtained by using mixer had higher turbidity and in-creases the load of clarification of juice. Comeroglu et al (1992) showed that juice yield of pomegranate was 50 percent of its whole fruit and 60 percent of arils.

Effect of different extraction methods on chemi-cal parameters of Pomegranate juice

The TSS, acidity, $\mathrm{pH}$, total sugar, reducing sugar and non-reducing sugar in juice extracted by method M1 for Ganesh cultivar were $15^{\circ} \mathrm{Bx}, 0.3$ percent, 3.2, 13.00 percent, 12.30 percent and 1.7 percent. Whereas juice extracted by method M2 showed values were $15.50^{\circ} \mathrm{Bx}, 0.32$ percent, 3.1, 13.50 percent, 12.00 percent and 1.5 percent respectively. It was observed that there was slight increase in TSS in method M2 due to crushing of seeds. In case of Arakta cultivar there is slight change in values of chemical parameters like Ganesh variety.

Miguel et al (2004) reported that there is no signifi-cant difference in content of sugars, acidity in juices obtained through application of different extraction methods.

Polyphenols are most prominent antioxidants in our diet. Among polyphenols, anthocyanins are predomi-nant group of polyphenol with high colouring poten-tial (Wrolostad et al 2005). Ascorbic acid is also well known for its antioxidant properties. It was found that the concentration of exreacted anthocyanins and ascorbic acid were found to be more by domestic mix er extraction meth- 
Table 1: Effect of extraction method on yield of pomegranate juice

\begin{tabular}{|c|c|c|}
\hline \multirow{2}{*}{ Variety } & \multicolumn{2}{|c|}{ Juice Yield (\%) } \\
\cline { 2 - 3 } & On basis of whole fruit & $\begin{array}{c}\text { On basis of weight of } \\
\text { arils }\end{array}$ \\
\hline Ganesh M1 & 50.25 & 65.8 \\
\hline Arakta M1 & 50.2 & 66.5 \\
\hline Ganesh M2 & 55.5 & 70.5 \\
\hline Arakta M2 & 55 & 72 \\
\hline S.E. & 0.335 & 0.422 \\
\hline C.D. & 1.093 & 1.375 \\
\hline
\end{tabular}

M1: Hand Press Method1 M2: domestic Mixer Method2

Table 2: Effect of different extraction methods on chemical parameters of Pomegranate juice

\begin{tabular}{|c|c|c|c|c|c|c|}
\hline \multirow{2}{*}{ Juice extraction method } & \multicolumn{7}{|c|}{ Parameter } \\
\cline { 2 - 7 } & $\begin{array}{c}\mathbf{T S S} \\
\mathbf{(} \mathbf{B x})\end{array}$ & $\begin{array}{c}\text { Acidity } \\
\mathbf{( \% )}\end{array}$ & $\mathbf{p H}$ & $\begin{array}{c}\text { Total } \\
\text { sug-ars } \\
\mathbf{( \% )}\end{array}$ & $\begin{array}{c}\text { Non- } \\
\text { Reducing } \\
\text { sugars (\%) }\end{array}$ & $\begin{array}{c}\text { Nodugars (\%) } \\
\text { suging }\end{array}$ \\
\hline GM1 & 15 & 0.3 & 3.2 & 13 & 12.3 & 1.7 \\
\hline AM1 & 14 & 0.32 & 3.2 & 13.5 & 12.3 & 1.2 \\
\hline GM2 & 15.5 & 0.32 & 3.1 & 13.5 & 12 & 1.5 \\
\hline AM2 & 14.5 & 0.35 & 3.2 & 14 & 12.8 & 1.2 \\
\hline S.E. & 0.381 & 0.013 & 0.057 & 0.354 & 0.287 & 0.115 \\
\hline C.D. & 1.243 & 0.044 & 0.187 & 1.555 & 0.935 & 0.375 \\
\hline
\end{tabular}

Each value is mean of triplicate determinations

M1: Hand Press Method1 M2: domestic Mixer Method2 G: Ganesh variety A: Arakta variety

Table 3: Effect of Extraction Methods on Antioxidant Properties of Pomegranate Juice

\begin{tabular}{|c|c|c|}
\hline \multirow{2}{*}{$\begin{array}{c}\text { Juice extraction } \\
\text { method }\end{array}$} & \multicolumn{2}{|c|}{ Parameter } \\
\cline { 2 - 3 } & Anthocyanin $\mathbf{( m g / 1 0 0 m l )}$ & Ascorbic Acid (mg/100g) \\
\hline GM1 & 4.5 & 8.5 \\
\hline AM1 & 16 & 18.2 \\
\hline GM2 & 7.25 & 9 \\
\hline AM2 & 18.2 & 9.5 \\
\hline S.E. & 0.167 & 0.24 \\
\hline C.D. & 0.542 & 0.786 \\
\hline
\end{tabular}

Each value is meanof triplicate determinations

M1: Hand Press Method1 M2: domestic Mixer Method2

G: Ganesh variety A: Arakta variety

od.

Anthocyanin content in Arakta cultivar was higher 16-18.20 $\mathrm{mg} / 100 \mathrm{ml}$ juice than anthocyanin content in Ganesh cultivar $4.50-7.25 \mathrm{mg} / 100 \mathrm{ml}$ juice. The results reported in Table 3 showed the lower total anthocy-anins values than the results reported by Cam et al., (2009). Ascorbic acid content in Ganesh cultivar was $8.5-9 \mathrm{mg} / 100 \mathrm{~g}$ and in Arakta cultivar $9.2-9.5 \mathrm{mg} / 100 \mathrm{~g}$.

The values obtained in the current study are in agree-ment with the results reported by Kulkarni and Arad-hya (2005).

It is observed from Table 4 that there was not much variation in mineral content in both the cultivars as well as for different extraction methods. The results obtained were similar with results reported by Chavan et al (1995).

It is observed from Table 5 that sample A1 scored highest score for overall acceptability was 8.5 than A, G and G1 7, 7.5 and 8 respectively. The sample A1 scored higher 8.5 for overall acceptabil- 
Table 4: Effect of Extraction Methods on Mineral Content of Pomegranate Juice

\begin{tabular}{|c|c|c|c|c|c|c|c|}
\hline \multirow{2}{*}{$\begin{array}{c}\text { Juice extrac } \\
\text { tion method }\end{array}$} & \multicolumn{7}{|c|}{ Mineral (mg/100g) } \\
\cline { 2 - 8 } & Calcium & $\begin{array}{c}\text { Phos- } \\
\text { phorus }\end{array}$ & Potassium & Iron & Zinc & Copper & $\begin{array}{c}\text { Manga- } \\
\text { nese }\end{array}$ \\
\hline GM1 & 5 & 60 & 132 & 1.3 & 0.8 & 0.3 & 0.7 \\
\hline AM1 & 6 & 55 & 130 & 1.4 & 0.79 & 0.32 & 0.75 \\
\hline GM2 & 6 & 65 & 133 & 1.35 & 0.82 & 0.32 & 0.72 \\
\hline AM2 & 7 & 50 & 132 & 1.45 & 0.8 & 0.34 & 0.77 \\
\hline S.E. & 0.377 & 0.421 & 0.484 & 0.154 & 0.019 & 0.025 & 0.022 \\
\hline C.D. & 1.229 & 1.404 & 1.578 & 0.501 & 0.063 & 0.081 & 0.073 \\
\hline
\end{tabular}

Each value is mean of triplicate determinations

M1: Hand Press Method1 M2: domestic Mixer Method2

G: Ganesh variety A: Arakta variety

Table 5: Sensory evaluation of spiced pomegranate juice

\begin{tabular}{|c|c|c|c|c|c|}
\hline \multirow{2}{*}{$\begin{array}{c}\text { Sample } \\
\text { Code }\end{array}$} & \multicolumn{4}{|c|}{ Sensory Attributes } \\
\cline { 2 - 6 } & Colour & $\begin{array}{c}\text { Appear- } \\
\text { ance }\end{array}$ & Flavor & Taste & $\begin{array}{c}\text { Overall Accept- } \\
\text { ability }\end{array}$ \\
\hline A & 7 & 7 & 7 & 8 & 7 \\
\hline A1 & 8.5 & 8.5 & 8.5 & 8.5 & 8.5 \\
\hline G & 8 & 8 & 7 & 7 & 7.5 \\
\hline G1 & 7 & 8 & 8 & 8 & 7.8 \\
\hline S.E. & 0.381 & 0.456 & 0.381 & 0.44 & 0.483 \\
\hline C.D. & 1.243 & 1.486 & 1.243 & 1.435 & 1.572 \\
\hline
\end{tabular}

$\mathrm{A}=$ Pomegranatejuice $\mathrm{Cv}$. Arakta

$\mathrm{A} 1=$ Spiced pomegranate juice of $\mathrm{Cv}$. Arakta

$\mathrm{G}=$ Pomegranate juice Cv. Ganesh

$\mathrm{G} 1=$ Spiced pomegranate juice of Cv. Ganesh

Table 6: Effect of storage temperature on quality of juiceriety

\begin{tabular}{|c|c|c|c|c|c|c|c|}
\hline \multirow[b]{2}{*}{ Storage Period } & \multicolumn{7}{|c|}{ Parameter } \\
\hline & $\begin{array}{l}\text { TSS } \\
\left({ }^{0} \mathrm{Bx}\right)\end{array}$ & $\begin{array}{c}\text { Acidity } \\
(\%)\end{array}$ & $\mathrm{pH}$ & $\begin{array}{c}\text { Ascorbic acid } \\
(\mathrm{mg} / 100 \mathrm{~g})\end{array}$ & Total sugars(\%) & $\begin{array}{c}\text { Reducing sugars } \\
(\%)\end{array}$ & $\begin{array}{c}\text { Non-re- } \\
\text { ducing } \\
\text { sugars } \\
(\%)\end{array}$ \\
\hline 0 days(fresh) & 15 & 0.4 & 3.1 & 8.5 & 13 & 12.5 & 1.2 \\
\hline After 60 days at & 6 & 55 & 130 & 1.4 & 0.79 & 0.32 & 0.75 \\
\hline Ambient temp. & 15.5 & 0.32 & 3.3 & 6.5 & 14.3 & 12.9 & 1.4 \\
\hline After 60 days at & 7 & 50 & 132 & 1.45 & 0.8 & 0.34 & 0.77 \\
\hline Refrigeration temp. & 16 & 0.35 & 3.2 & 6.8 & 14.25 & 12.8 & 1.45 \\
\hline S.E. & 0.288 & 0.017 & 0.81 & 0.173 & 0.106 & 0.111 & 0.036 \\
\hline C.D. & 0.997 & 0.05 & 0.282 & 0.598 & 0.368 & 0.386 & 0.124 \\
\hline
\end{tabular}

Table 7: Energy value of prepared products 
Table 8: Cost of spiced pomegranate juice

\begin{tabular}{|c|c|c|c|c|}
\hline Sr.No & Particular & Quantity & Price PerUnit (Rs.) & Cost (Rs.) \\
\hline 1 & Pomegranate & $2 \mathrm{~kg}$ & $40 / \mathrm{kg}$ & $80 /-$ \\
\hline 2 & Cardamom & $20 \mathrm{~g}$ & $15 / 10 \mathrm{~g}$ & $30 /-$ \\
\hline 3 & Clove & $10 \mathrm{~g}$ & $15 / 10 \mathrm{~g}$ & $15 /-$ \\
\hline 4 & Fennel & $20 \mathrm{~g}$ & $20 / 100 \mathrm{~g}$ & $5 /-$ \\
\hline 5 & & Total raw material cost & $130 /-$ \\
\hline 6 & Processing and Packaging cost @ 15\% of raw material cost & $20 /-$ \\
\hline 7 & \multicolumn{2}{|c|}{ Production cost for 1 liter of flavored juice } & $150 /-$ \\
\hline 8 & \multicolumn{2}{r|}{ Production cost of 200 ml of flavored juice } & $30 /-$ \\
\hline
\end{tabular}

The production cost of pomegranate spiced pomegranate juice is worked out in Table 7.

Production cost of $200 \mathrm{ml}$ of flavored pomegranate juice $=$ Rs. $30 /-$

ity among other samples may be due to colour of Arakta Cultivar com-pared to Ganesh cultivar and addition of spice extract than control i.e. without addition of spices. Flavored spicy pomegranate juice remarkably improved organo-leptic quality.

\section{Effect of storage temperature on quality of juice}

It is observed from values in Table 6 that values of TSS, Total sugars, reducing sugars and non-reducing sugar of pomegranate juice increased during storage. It was noted that TSS of juice was initially $15^{\circ} \mathrm{Bx}$ and after 60 days it was $15.5^{\circ} \mathrm{Bx}$ at ambient temperature and $16^{\circ} \mathrm{Bx}$ at refrigeration temperature. Increase in TSS was found to be associated with increase in sugars.

These results were in agreement with those reported by Palaniswamy and Muthukrishnan (1974).

It was found that total sugar, reducing sugars and non-reducing sugar content was increased during storage at both room and refrigeration temperature. The $\mathrm{pH}$ of juice showed not much change during storage. Acidity and ascorbic acid content of juice showed decreasing trend during storage period. This decrease in acidity could be due to chemical interactions between organic constituents of the juice particularly organic acids and anthocyanins Palaniswamy and Muthukrishnan (1974). Similar results were reported by Khurdiya and Anand (1981). At room temperature juice when stored for two months decrease in ascorbic acid from $8.5 \mathrm{mg} / 100 \mathrm{~g}$ to $6.5 \mathrm{mg} / 100 \mathrm{~g}$ was observed. While at refrigeration tem-perature ascorbic acid was found to be reduced upto 6.8 $\mathrm{mg} / 100 \mathrm{~g}$.

\section{Conclusion}

It can be concluded that a good quality spiced pome-granate juice can be prepared from pomegranate fruits. In case of extraction methods for juice extraction, the domestic mixer method was found in relation to yield and other quality characteristics like TSS.Pomegranate cultivar Arakta is suitable for preparation of highly nu-tritive and palatable spiced Pomegranate juice with its attractive colour Hence this product could be recom-mended for commercial exploitation...Nevertheless, the pomegranate has commercial potential for production of health related food products. But the systematic and organized approach should be followed with other so-phisticated methods for retention of other bio-active components, storage life, clinical studies and packaging requirements.

\section{References}

[1]. AOAC (1990) Official methods of analysis of the associa-tion of official analytical chemists (15thedition), Washington D.C.:992-995.

[2]. Amerine M A, Pangborn R M and Roessler E V (1987) Prin-ciples of Sensory Evaluation of Food. Academic Press, New York. PP: 349-397.

[3]. Cam M, Durmaz G, Hisil Y (2009) Classification of eight pomegranate juices based on antioxidant capacity measured by four methods. Food Chem. 112:721-726.

[4]. Chavan U D, Adsule R N and Kadam S S (1995) Physico-chemical properties of pomegranate (Punica granatum L.) rind powder. Beverage Food World. 22(1):36.

[5]. Comeroglu B, Artik N and Erbas S (1992) Gewinnung von granatapfel saft and seine zusammensetzung. Fillissiques. Obst. 59:335-340

[6]. Esmaillzadeh A, Tahbaz F, Gaieni I, Alavi-Majd H and Azad-bakht L (2004) Concentrated pomegranate juice improves li-pid profiles in diabetic patients with hyperlipidemia. J. Medic. Food. 7(3):305-308.

[7]. Khurdiya D S and Anand J C (1981) Effect of extraction method, container and storage temperature of Phalsa fruit juice. Indian Food Packer. 35(6):6871.

[8]. Kulkarni A P and Aradhya S M (2005) Chemical changes and antioxidant activity in pomegranate arils during fruit develop-ment. Food Chem. 93:319-324.

[9]. La Rae R H (1969) Agric. Expt. Station. University of Cali-fornia. Leaflet. 305-313.

[10]. Miguel G, Dandlen S, Antunes D, Neves A and Martins D (2004) The effect of two different methods of pomegranate (Punica granatum L) juice extraction on quality during stor-age at 40C. J. Biomed. Biotech., 5:332-337.

[11]. Palaniswamy K P and Muthukrishnan C R (1974) Studies on the physicochemical characters of lemon juice and squash during storage. Indian Food Packer. 28(4):37-41.

[12]. Panse V.S. and Sukhatme P.V. (1967). Statistical Methods for Agricultural Workers. Indian Council of Agricultural Re-search. New Delhi, pp70-72.

[13]. Seeram NP, Aviram M, Zhang Y, Henning SM, Feng L, Dre-her M and Herber D (2008) Comparison of antioxidant po-tency of commonly consumed polyphenol-rich beverages in the United States. J. Agric Food Chem. 56(4):1415-1422.

[14]. Wrolstad R E, Durst R W and Lee J (2005) Tracking colour and pigment changes in anthocyanin. Trends in Food Sci. Tech. 16:423-428. 